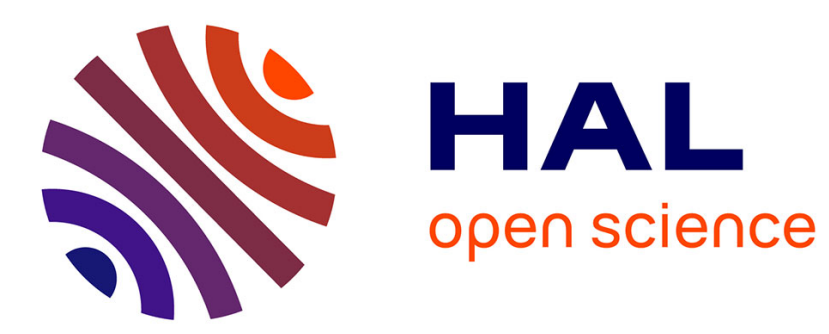

\title{
Kinetic and Mechanistic Study of the Thermal Decomposition of Ethyl Nitrate
}

\author{
Julien Morin, Yuri Bedjanian
}

\section{To cite this version:}

Julien Morin, Yuri Bedjanian. Kinetic and Mechanistic Study of the Thermal Decomposition of Ethyl Nitrate. International Journal of Chemical Kinetics, 2017, 49 (5), pp.354 - 362. 10.1002/kin.21080 . hal-01804101

\section{HAL Id: hal-01804101 \\ https://hal.science/hal-01804101}

Submitted on 14 Jan 2022

HAL is a multi-disciplinary open access archive for the deposit and dissemination of scientific research documents, whether they are published or not. The documents may come from teaching and research institutions in France or abroad, or from public or private research centers.
L'archive ouverte pluridisciplinaire HAL, est destinée au dépôt et à la diffusion de documents scientifiques de niveau recherche, publiés ou non, émanant des établissements d'enseignement et de recherche français ou étrangers, des laboratoires publics ou privés. 


\title{
Kinetic and Mechanistic Study of the Thermal Decomposition of Ethyl Nitrate
}

\author{
JULIEN MORIN and YURI BEDJANIAN*
}

Institut de Combustion, Aérothermique, Réactivité et Environnement (ICARE), CNRS and Université d'Orléans, 45071 Orléans Cedex 2, France

ABSTRACT. Thermal decomposition of ethyl nitrate $\left(\mathrm{CH}_{3} \mathrm{CH}_{2} \mathrm{ONO}_{2}\right.$, ENT) has been studied in a low pressure flow reactor combined with a quadrupole mass spectrometer. The rate constant of the nitrate decomposition was measured as a function of pressure (1 -12.5 Torr of helium) and temperature in the range $464-673 \mathrm{~K}$ using two different approaches: from kinetics of ENT loss and those of the formation of the reaction product $\left(\mathrm{CH}_{3}\right.$ radical). The fit of the observed falloff curves with two parameter expression $k_{1}=\frac{k_{0} k_{\infty}[M]}{k_{0}[M]+k_{\infty}} \times 0.6^{\left(1+\left(\log \left(\frac{k_{0}[M]}{k_{\infty}}\right)\right)^{2}\right)^{-1}}$ provided the following low and high pressure limits for the rate constant of ENT decomposition: $k_{0}=1.0 \times 10^{-4} \exp (-16400 / \mathrm{T}) \mathrm{cm}^{3}$ molecule $^{-1} \mathrm{~s}^{-1}$ and $k_{\infty}$ $=1.08 \times 10^{16} \exp (-19860 / \mathrm{T}) \mathrm{s}^{-1}$, respectively, which allow to reproduce (via above expression and with $20 \%$ uncertainty) all the experimental data obtained for $k_{1}$ in the temperature and pressure range of the study. It was observed that the initial step of the thermal decomposition of ethyl nitrate is $\mathrm{O}-\mathrm{NO}_{2}$ bond cleavage leading to formation of $\mathrm{NO}_{2}$ and $\mathrm{CH}_{3} \mathrm{CH}_{2} \mathrm{O}$ radical, which rapidly decomposes to form $\mathrm{CH}_{3}$ and formaldehyde as final products. The yields of $\mathrm{NO}_{2}, \mathrm{CH}_{3}$ and formaldehyde upon decomposition of ethyl nitrate were measured to be near unity. In addition, the kinetic data were used to determine the $\mathrm{O}-\mathrm{NO}_{2}$ bond dissociation energy in ethyl nitrate: $38.3 \pm 2.0 \mathrm{kcal} \mathrm{mol}^{-1}$.

Keywords: ethyl nitrate, thermal decomposition, rate constant, falloff curve, ethoxy radical.

*Correspondence to: Yuri Bedjanian: Tel.: +33 238255474, e-mail: yuri.bedjanian@cnrs-orleans.fr. Supporting Information is available in the online issue at www.wileyonlinelibrary.com. 


\section{INTRODUCTION}

Organic nitrates are important species in atmospheric and combustion chemistry. In the atmosphere, they are formed in a minor addition channel of the reaction of peroxy radicals with $\mathrm{NO}$ and also in the $\mathrm{NO}_{3}$-initiated oxidation of unsaturated organic compounds [1]. Organic nitrates are considered as stable species with atmospheric lifetimes of several days or weeks (depending on their photolysis rate and reactivity toward $\mathrm{OH}$ radicals) [2], and represent reservoirs of reactive nitrogen. In combustion processes, nitrates, used as fuel additives, are known to promote the ignition of diesel fuel. Production of chain-initiating radicals and, possibly, the heat released during nitrate decomposition in the pre-ignition phase are thought to decrease the ignition-delay time [3-5].

Thermal decomposition of acyclic nitrates is supposed to proceed through a radical mechanism with initial dissociation of the $\mathrm{O}-\mathrm{NO}_{2}$ bond leading to formation of $\mathrm{NO}_{2}$ and alkoxy radical $(\mathrm{RO})$ :

$$
\mathrm{RONO}_{2} \rightarrow \mathrm{RO}+\mathrm{NO}_{2}
$$

The alkoxy radicals can undergo a number of competing reaction pathways, including unimolecular decomposition, which usually occurs through $\mathrm{C}-\mathrm{C}$ bond fission to produce a carbonyl compound, and a unimolecular isomerization, which generates a hydroxy-substituted alkyl radical [6].

Although thermal decomposition of nitrates has been studied previously for several times [7-15], available quantitative information on the rate constants and products of these reactions is very scarce. In our recent paper [16], we have reported the results of the experimental study of the kinetics and products of the thermal decomposition of isopropyl nitrate. In the present work, we applied the similar experimental approach to study thermal decomposition of ethyl nitrate (ENT), including the measurements of the rate constant as a function of pressure and temperature and identification and quantification of the reaction products: 
$\mathrm{CH}_{3} \mathrm{CH}_{2} \mathrm{ONO}_{2}(+\mathrm{M}) \rightarrow$ products

\section{EXPERIMENTAL}

Thermal decomposition of ethyl nitrate was studied at total pressure of helium between 1 and 12.5 Torr and in the temperature range (464 - 673) K. Experiments were carried out in a flow reactor under laminar flow conditions using a modulated molecular beam electron impact ionization (with ion source operating at $25-30 \mathrm{eV}$ ) mass spectrometer as the detection method [16,17]. The flow reactor (Figure 1) consisted of a Quartz tube (45 cm length and $2.5 \mathrm{~cm}$ i.d.) with an electrical heater and water-cooled extremities [17]. Temperature in the reactor was measured with a $K$-type thermocouple positioned in the middle of the reactor in contact with its outer surface. Temperature gradient along the flow tube measured with a thermocouple inserted in the reactor through the movable injector was less than $1 \%$ [17].

Ethyl nitrate was introduced into the flow reactor from a 10L flask containing nitrate-He mixture or (when high concentrations of ENT were needed) by passing helium through a thermostated glass bubbler containing liquid nitrate. The inner tube of the injector, through which nitrate was supplied, was thermally insulated in order to minimize the possible decomposition of ENT prior its introduction into the main reactor (Figure 1). Ethyl nitrate was detected by mass spectrometry at its fragment peak at $m / z=76\left(\mathrm{CH}_{2} \mathrm{ONO}_{2}{ }^{+}\right)$, which is much more intensive than the parent one (at $m / z=91) . \mathrm{CH}_{3}$ radicals were detected as $\mathrm{CH}_{3} \mathrm{Br}$ at $\mathrm{m} / \mathrm{z}$ $=94 / 96\left(\mathrm{CH} 3 \mathrm{Br}^{+}\right)$after being scavenged by an excess of $\mathrm{Br}_{2}$ via reaction:

$$
\begin{aligned}
& \mathrm{CH}_{3}+\mathrm{Br}_{2} \rightarrow \mathrm{CH}_{3} \mathrm{Br}+\mathrm{Br} \\
& k_{2}=2.0 \times 10^{-11} \exp (197 / T) \mathrm{cm}^{3} \text { molecule } \mathrm{s}^{-1}(T=296-532 \mathrm{~K})[18]
\end{aligned}
$$

All other species were detected at their parent peaks: $m / z=30$ (formaldehyde, $\mathrm{CH}_{2} \mathrm{O}^{+}$), 160 $\left(\mathrm{Br}_{2}^{+}\right), 46\left(\mathrm{NO}_{2}^{+}\right)$ 
The absolute calibration of mass spectrometer for formaldehyde was realized by injecting known amounts $(0.2-0.8 \mu \mathrm{L})$ of the $36.5 \%$ wt solution of $\mathrm{CH}_{2} \mathrm{O}$ in water inside the flow tube, and recording the parent mass peak intensity of $\mathrm{CH}_{2} \mathrm{O}$ at $\mathrm{m} / \mathrm{z}=30$. The integrated area of the mass spectrometric signals corresponding to known total number of $\mathrm{CH}_{2} \mathrm{O}$ molecules injected into the reactor allowed the determination of the calibration factor. The flow rates, and consequently the absolute concentrations, of all other stable species in the reactor were determined from the measurements of the pressure drop of mixtures of the species with helium in calibrated volume flasks.

Ethyl nitrate was synthesized in the laboratory via slow mixing of ethanol with $\mathrm{H}_{2} \mathrm{SO}_{4}: \mathrm{HNO}_{3}(1: 1)$ mixture at temperature $<5^{\circ} \mathrm{C}[19,20]$. The synthesized nitrate was degassed before use. Gas chromatographic analysis of the ethyl nitrate has shown that impurities were less than $0.1 \%$. The purities and origin of other gases used were as follows: $\mathrm{He}>99.9995 \%$ (Alphagaz, France); $\mathrm{Br}_{2}>99.99 \%$ (Aldrich, France); $\mathrm{NO}_{2}>99 \%$ (Alphagaz, France); $36.5 \%$ wt solution of formaldehyde in water (Sigma-Aldrich, France).

\section{RESULTS AND DISCUSSION}

Two different methods were employed for the measurements of the rate of nitrate decomposition [16]. The first one, used at higher temperatures $(\mathrm{T}=575-673 \mathrm{~K})$ consisted in a direct monitoring of the kinetics of nitrate loss. In the second approach employed at lower temperatures $(\mathrm{T}=464-583 \mathrm{~K})$, where consumption of nitrate was too low to be measured accurately, the rate constant was determined from the kinetics of product $\left(\mathrm{CH}_{3}\right.$ radical $)$ formation.

\section{Kinetics of the ethyl nitrate decomposition}

In this series of experiments the rate constant of reaction (1) was determined in the temperature range 575 - $673 \mathrm{~K}$ from the kinetics of ethyl nitrate loss due to its decomposition. 
It was observed that at a given total pressure consumption of nitrate follows first order kinetics: $\mathrm{d}[\mathrm{ENT}] / \mathrm{d} t=-k_{1}[\mathrm{ENT}]$. Example of the exponential decays of ENT observed at different pressures in the reactor at $\mathrm{T}=634 \mathrm{~K}$ is shown in Figure 2. The values of $k_{1}\left(\right.$ in s $\left.\mathrm{s}^{-1}\right)$ determined from the kinetics of ENT loss (like those shown in Figure 2) at different temperatures in the reactor are plotted in Figure 3 as a function of total pressure. The values of $k_{1}$ were corrected for axial and radial diffusion of ENT. The corrections were generally less than $5 \%$. The uncertainty on the measurements of $k_{1}$ was estimated to be nearly $10 \%$, including statistical error (within a few percent) and those on the measurements of the flows $(5 \%)$, pressure $(2 \%)$ and temperature $(1 \%)$. One can note that in the pressure range of the present study, decomposition of the nitrate proceeds in the "falloff regime" (Figure 3). One of the simplest approaches to rationalize the dependence of the rate constant on pressure in falloff regime is based on the Lindemann-Hinshelwood reaction scheme:

$$
\begin{aligned}
& \mathrm{AB}+\mathrm{M} \leftrightarrows \mathrm{AB}^{*}+\mathrm{M} \\
& \mathrm{AB}^{*} \rightarrow \mathrm{A}+\mathrm{B}
\end{aligned}
$$

This reaction scheme, under assumption of quasi-stationary concentrations for the excited unstable species $\mathrm{AB}^{*}$, provides the following expression for the rate constant of the dissociation reaction:

$$
k=\frac{k_{0} k_{\infty}[\mathrm{M}]}{k_{0}[\mathrm{M}]+k_{\infty}}
$$

where $k_{0}=k_{3}$ and $k_{\infty}=k_{3} k_{4} / k_{-3}$ are low and high pressure limits of the rate constant, respectively. The experimental data for the rate constant $k$ as a function of $[\mathrm{M}]$ can be fitted accordingly to equation (I) with two variable parameters, $k_{0}$ and $k_{\infty}$. However, in practice, the Lindemann-Hinshelwood expressions do not characterize the fall-off curves completely and should be modified. This is usually done by adding a broadening factor, $F$, to the LindemannHinshelwood expressions, leading to [21,22]: 


$$
k=\frac{k_{0} k_{\infty}[\mathrm{M}]}{k_{0}[\mathrm{M}]+k_{\infty}} F=k_{0}[\mathrm{M}]\left(\frac{1}{1+k_{0}[\mathrm{M}] / k_{\infty}}\right) F
$$

with broadening factor $F$ determined as:

$$
\log F \cong \frac{\log F_{C}}{1+\left(\frac{\log \left(k_{0}[\mathrm{M}] / k_{\infty}\right)}{N}\right)^{2}}
$$

with $N=0.75-1.27 \log F_{\mathrm{c}}[21,22]$. So the falloff curve is characterized by three parameters, $k_{0}, k_{\infty}$ and $F_{\mathrm{c}}$ (called "center broadening factor"), all being reaction- and temperaturedependent. In practice, it is impossible to fit a limited part of falloff curve, usually determined in experiments, with three variable parameters. In the present study, as in previous one on decomposition of isopropyl nitrate [16], in order to describe the dependence of the rate constant on pressure we adopted simplified approach used in JPL evaluation of kinetic data [23]: the experimental falloff curve was fitted accordingly to equations (II) and (III) with fixed and independent of temperature $F_{\mathrm{c}}=0.6$ and $N=1$ and two varied parameters, $k_{0}$ and $k_{\infty}$. Obviously, $k_{0}$ and $k_{\infty}$ determined in this way depend on the choice of $F_{\mathrm{c}}$-value, nevertheless this procedure allows to describe the experimental data with the three clearly specified parameters.

Continuous lines in Figure 3 represent the fit to experimental data according to equations (II) and (III) with $F_{\mathrm{c}}=0.6$, providing the values of $k_{0}$ and $k_{\infty}$ at different temperatures, which are summarized in Table I. The measurements of $k_{1}$ were carried out with initial concentration of ENT of nearly $10^{12}$ molecule $\mathrm{cm}^{-3}$. In a special series of experiments carried out at $\mathrm{P}=4.05$ torr and $\mathrm{T}=651 \mathrm{~K}$ we have verified for the possible influence of the initial concentration of ENT on the measured values of $k_{1}$. The rate of ENT decomposition was found to be independent (within 5\%) of $[\mathrm{ENT}]_{0}$ (Figure S1 in Supporting Information), the last being varied in the range $(0.36-3.10) \times 10^{12}$ molecule $\mathrm{cm}^{-3}$. 
Heterogeneous decomposition of ethyl nitrate could potentially impact the measured rates of the nitrate loss. Adams \& Bawn [8] in their study of ethyl nitrate decomposition under static conditions reported that a 7.4 times increase in surface of a Pyrex reaction vessel had no influence on the reaction rate at $\mathrm{T}=456 \mathrm{~K}$, indicating on a limited impact of the wall processes. This finding allows to expect a negligible (compared with homogeneous process) heterogeneous loss of ENT in our fast flow quartz reactor, although in the present study the wall decomposition of ENT was not tested.

\section{Reaction products}

Thermal decomposition of ethyl nitrate is expected to proceed through initial dissociation of the $\mathrm{O}-\mathrm{NO}_{2}$ bond leading to formation of $\mathrm{NO}_{2}$ and ethoxy radical:

$$
\mathrm{CH}_{3} \mathrm{CH}_{2} \mathrm{ONO}_{2} \rightarrow \mathrm{CH}_{3} \mathrm{CH}_{2} \mathrm{O}+\mathrm{NO}_{2}
$$

The $\mathrm{CH}_{3} \mathrm{CH}_{2} \mathrm{O}$ radicals can undergo unimolecular decomposition through the following two competitive reaction pathways $[6,24,25]$ :

$$
\begin{aligned}
& \mathrm{CH}_{3} \mathrm{CH}_{2} \mathrm{O} \rightarrow \mathrm{CH}_{3}+\mathrm{CH}_{2} \mathrm{O} \\
& \mathrm{CH}_{3} \mathrm{CH}_{2} \mathrm{O} \rightarrow \mathrm{H}+\mathrm{CH}_{3} \mathrm{CHO}
\end{aligned}
$$

Based on the rate constants calculated for reactions (5a) and (5b) $[6,24,25]$, one could expect that under experimental conditions of the present study, firstly, $\mathrm{CH}_{3}$ forming channel (5a) is the dominant one $\left(k_{5 \mathrm{~b}} / k_{5 \mathrm{a}}<0.1\right)$ and, secondly, decomposition of the ethoxy radical is very rapid on the timescale of our experiments $\left(k_{5 \mathrm{a}}>10^{3} \mathrm{~s}^{-1}\right)$. Indeed, we have observed the formation of $\mathrm{NO}_{2}, \mathrm{CH}_{3}$ and formaldehyde $\left(\mathrm{CH}_{2} \mathrm{O}\right)$ upon decomposition of ethyl nitrate in the flow reactor. Example of the kinetics of the products formation along with that of ENT decay is shown in Figure 4. These data were obtained in the presence of $\operatorname{Br}_{2}\left(\sim 5 \times 10^{13}\right.$ molecule $\mathrm{cm}^{-}$

${ }^{3}$ ) which was added in the reactor in order to transform (via reaction 2) $\mathrm{CH}_{3}$ radicals, once formed, into the stable species, $\mathrm{CH}_{3} \mathrm{Br}$, which was recorded with mass spectrometer and to avoid possible consumption of the radicals in secondary reactions. It is worth noting that the 
rate of $\mathrm{CH}_{3}$ radical loss on the wall of the flow reactor $\left(<30 \mathrm{~s}^{-1}\right.$ in the temperature range of the study) was negligible compared with that of the $\mathrm{CH}_{3}$ reaction with $\mathrm{Br}_{2}$. Temporal profile of ENT in Figure 4 is fitted (solid line) with an exponential function. Three other curves in Figure 4 are traced in accordance with the following equation:

$$
[\text { Product }]=\alpha \times[\mathrm{ENT}]_{0} \times\left(1-\exp \left(-k_{1} \times \mathrm{t}\right),\right.
$$

where $k_{1}$ is the rate constant of ENT decomposition and $\alpha$ is the yield of the reaction product. Solid and dashed curves corresponding to $\alpha=1$ and $\alpha=1 \pm 0.1$, respectively, demonstrate nearly one hundred percent yield of the reaction products. There is an important contribution of ethyl nitrate to the MS signals of $\mathrm{NO}_{2}$ and $\mathrm{CH}_{2} \mathrm{O}$ due to its fragmentation in the ion source of the mass spectrometer. That is why the quantitative measurements of the yields of the three reaction products were carried out at relatively high temperature, $\mathrm{T}=700 \mathrm{~K}$, under conditions where complete decomposition of ENT was observed. Experiments consisted in the monitoring of the concentrations of the products formed upon total decomposition of ENT in the reactor in the presence of relatively high concentration of $\mathrm{Br}_{2}\left(\left[\mathrm{Br}_{2}\right] \sim 5 \times 10^{13}\right.$ molecule $\mathrm{cm}^{-}$ ${ }^{3}$ ) in order to transform $\mathrm{CH}_{3}$ radicals into $\mathrm{CH}_{3} \mathrm{Br}$. Initial concentration of ENT was varied in the range $(0.15-2.37) \times 10^{12}$ molecule $\mathrm{cm}^{-3}$. The results of these experiments are shown in Figure 5. The slopes of the straight lines in Figure 5 provide the yields of the corresponding species:

$$
\begin{aligned}
& \Delta\left[\mathrm{NO}_{2}\right] / \Delta[\mathrm{ENT}]=1.00 \pm 0.15, \\
& \Delta\left[\mathrm{CH}_{2} \mathrm{O}\right] / \Delta[\mathrm{ENT}]=0.96 \pm 0.15, \\
& \Delta\left[\mathrm{CH}_{3}\right] / \Delta[\mathrm{ENT}]=0.97 \pm 0.15,
\end{aligned}
$$

The estimated nearly $15 \%$ uncertainty on the measurements arises mainly from the combined errors on the measurements of the absolute concentrations of ENT and reaction products. These results confirm that the $\mathrm{O}-\mathrm{NO}_{2}$ bond cleavage is the initial step of ENT decomposition 
and $\mathrm{C}-\mathrm{C}$ bond fission leading to formation of $\mathrm{CH}_{3}$ and formaldehyde is the predominant decomposition pathway of the ethoxy radical under experimental conditions of the study.

\section{$\mathrm{CH}_{3}$ production kinetics}

In this series of experiments the rate constant of reaction (1) was determined in the temperature range 464 - $583 \mathrm{~K}$ from the kinetics of $\mathrm{CH}_{3}$ formation under conditions where consumption of nitrate was negligible and the rate constant could not be determined from the decays of ENT. $\mathrm{CH}_{3}$ radical was chosen among three products of ENT decomposition because mass spectra of $\mathrm{NO}_{2}$ and formaldehyde were highly perturbed by contribution of fragment peaks of ethyl nitrate which was present in the reactor at relatively high concentrations. $\mathrm{Br}_{2}$ was added in the reactor in order to convert $\mathrm{CH}_{3}$ radicals to $\mathrm{CH}_{3} \mathrm{Br}$, which was monitored by mass spectrometry. As one could expect, linear increase of $\mathrm{CH}_{3}$ concentration with reaction time was observed upon decomposition of ethyl nitrate (Figure S2 in Supporting information) in line with expression:

$$
\mathrm{d}\left[\mathrm{CH}_{3}\right] / \mathrm{d} t=k_{1} \times[\mathrm{ENT}]
$$

and under conditions where variation of ENT concentration with time was insignificant (< 10\%). The slopes of the straight lines in Figure $\mathrm{S} 2$ provide the rate of $\mathrm{CH}_{3}$ production, $\mathrm{d}\left[\mathrm{CH}_{3}\right] / \mathrm{d} t$ (in molecule $\mathrm{cm}^{-3} \mathrm{~s}^{-1}$ ), which is presented in Figure S3 (in Supporting information) as a function of initial concentration of ENT. The observed linear, in accordance with equation (IV), dependence of $\mathrm{d}\left[\mathrm{CH}_{3}\right] / \mathrm{d} t$ on $[\mathrm{ENT}]$ indicates negligible contribution of possible secondary reactions which could lead to $\mathrm{CH}_{3}$ production or consumption.

Example of kinetics of $\mathrm{CH}_{3}$ formation measured at different pressures in the reactor is shown in Figure 6. All the experimental data obtained for $k_{1}\left(k_{1}=1 /[\mathrm{ENT}] \times \mathrm{d}\left[\mathrm{CH}_{3}\right] / \mathrm{d} t\right)$ from the kinetics of $\mathrm{CH}_{3}$ production at different pressures and temperatures are shown in Figure 7. Procedure, similar to that used above in the case of ENT loss kinetics, was employed to extract low and high pressure limits of $k_{1}$ : continuous lines in Figure 7 represent the best fit to 
the experimental data according to equations (II) and (III) with $F_{\mathrm{c}}=0.6$ and two varied parameters, $k_{0}$ and $k_{\infty}$. The results obtained for $k_{0}$ and $k_{\infty}$ in this series of experiments are presented in Table I. Concerning the uncertainty on $k_{0}$ and $k_{\infty}$ derived from the fit of the falloff curves (with fixed value of $F_{\mathrm{c}}=0.6$ ) in Figures 3 and 7, it depends on the temperature of the measurements and has a different trend for low and high pressure limits of $k_{1}$. For example, it is obvious that at lower temperatures (Figure 7), the simulated falloff curve is more sensible to the value of $k_{\infty}$ and less to the value of $k_{0}$, because $k_{1}$ is relatively close to its high pressure limit. To keep things simple, we place a conservative (nearly maximum) estimated uncertainty of a factor of 1.5 on all the derived values of $k_{0}$ and $k_{\infty}$.

\section{Temperature dependence of $k_{1}$}

Temperature dependences of $k_{\infty}$ and $k_{0}$ are shown in Figure 8. One can note good agreement between the results obtained from the kinetics of ENT loss and $\mathrm{CH}_{3}$ production and that the combination of two approaches allowed the determination of the rate constants over a range of 5 to 6 orders of magnitude. Unweighted exponential fit to the experimental data in Figure 8 provides the following Arrhenius expressions: $k_{\infty}=6.49 \times 10^{15} \exp (-19550 / \mathrm{T}) \mathrm{s}^{-1}$ and $k_{0}=$ $1.35 \times 10^{-4} \exp (-16575 / \mathrm{T}) \mathrm{cm}^{3}$ molecule $\mathrm{s}^{-1}$. In the above analysis, the temperature dependence of the low and high pressure limits of the rate constant was determined from the individual values of these parameters determined at each temperature. We applied also another approach which consisted of a global fitting of all the experimental data simultaneously accordingly to equations (II) and (III) with fixed and independent of temperature $F_{\mathrm{c}}=0.6$ and $N=1$ and variable pre-exponential factors and activation energies in Arrhenius expressions for $k_{\infty}$ and $k_{0}$. The expressions for $k_{\infty}$ and $k_{0}$ obtained within this approach, which seems to be better in overall, did not differ significantly from those presented above and are recommended from the present study: 


$$
\begin{aligned}
& k_{\infty}=1.08 \times 10^{16} \exp (-19860 / \mathrm{T}) \mathrm{s}^{-1} \\
& k_{0}=1.0 \times 10^{-4} \exp (-16400 / \mathrm{T}) \mathrm{cm}^{3} \text { molecule }^{-1} \mathrm{~s}^{-1} .
\end{aligned}
$$

It should be emphasized again that the reported values of $k_{\infty}$ and $k_{0}$ depend on the choice of the $F_{\mathrm{c}}$-value used in the fitting of falloff curves and should be considered just as parameters allowing to represent the experimentally measured temperature and pressure dependence of $k_{1}$ as:

$$
k_{1}=\frac{k_{0} k_{\infty}[M]}{k_{0}[M]+k_{\infty}} \times 0.6^{\left(1+\left(\log \left(\frac{k_{0}[M]}{k_{\infty}}\right)\right)^{2}\right)^{-1}}
$$

This expression in combination with $k_{\infty}$ and $k_{0}$ given above reproduces all the temperature and pressure dependence data obtained for $k_{1}$ in the present study with accuracy within $20 \%$ and thus can be recommended for calculation of $k_{1}$ in the temperature range $464-673 \mathrm{~K}$ and $\mathrm{He}$ pressures between 1 and 12.5 Torr with conservative uncertainty of $20 \%$.

As noted above the absolute values of $k_{\infty}$ and $k_{0}$ determined in the present study depend on the $F_{\mathrm{c}}$-value used in calculations. We conducted an analysis of the sensitivity of $k_{\infty}$ and $k_{0}$ to the choice of the $F_{\mathrm{c}^{-}}$-value. For that the global fit of all the experimental data to expressions (II) and (III) was performed using different values of $F_{\mathrm{c}}$. The results obtained for low and high pressure limits of $k_{1}$ are shown in Table II. The last column in Table II shows the mean (for 65 experimental data points) of the ratios of calculated (using expressions (II) and (III) with different $F_{\mathrm{c}}$-factors and corresponding set of Arrhenius parameters) and experimental values of $k_{1}$. One can note that the experimental rate constant data can be described adequately and with a similar precision with any value of $F_{\mathrm{c}}$ between 0.3 and 0.8 . Example of the calculated with $F_{\mathrm{c}}=0.3$ and experimental data for $k_{1}$ is shown in Figure S4 in Supporting information. On the other hand, the activation energies, $E_{\infty}$ and $E_{0}$, are rather insensitive to the choice of $F_{\mathrm{c}}$-factors, and seem to be well defined by the measured values of $k_{1}$. Considering 
the data presented in Table II, we place a nearly 5\% uncertainty on the activation energies in Arrhenius expressions for $k_{\infty}$ and $k_{0}$ recommended above (for $F_{\mathrm{c}}=0.6$ and $N=1$ ): $E_{\infty}=$ $(19860 \pm 1000)$ and $E_{0}=(16400 \pm 500) \mathrm{K}$.

To our knowledge, the quantitative data on the rate constant of the ethyl nitrate decomposition were reported only in a few previous studies [8-10,14]. The earlier studies [810] were realized under static conditions using manometric method, reaction rate constant being determined from the increase of pressure at constant volume and temperature. Zaslonko et al. [14] in their shock tube study applied the absorption spectrophotometry to determine the reaction rate constant from kinetics of ENT loss and first stage of $\mathrm{NO}_{2}$ production. The authors noted that under their experimental conditions the decomposition of nitrate occurred in the falloff regime. All the data reported for $k_{1}$ in the previous studies are shown Table III. Straightforward comparison of the results obtained for $k_{1}$ in different studies is difficult considering that the measurements of $k_{1}$ were realized in falloff region (although close to high pressure limit) and with different bath gases. Nevertheless, one can note that the reported activation energies are very close (in the range $39.6 \pm 1.6 \mathrm{kcal} \mathrm{mol}^{-1}$, except ref. 14). In contrast, the values of the pre-exponential factors are highly scattered reflecting a low accuracy on the determination of $A$-factor from the experimental data obtained in a narrow temperature range. Even so, the difference between the absolute values of $k_{1}$ measured in different studies (Figure S5 in Supporting information) is not dramatic: the values of $k_{1}$ from different (at least, low temperature) studies agree with each other within a factor of 3 and are qualitatively consistent with the present data for $k_{\infty}$.

The activation energy obtained in the present study for $k_{\infty}, E_{\infty}=39.4 \pm 2.0 \mathrm{kcal} \mathrm{mol}^{-1}$, allows the determination of the $\mathrm{O}-\mathrm{NO}_{2}$ bond dissociation energy (BDE) in ethyl nitrate as $\mathrm{BDE}=E_{\infty}-R T_{\mathrm{av}}$, where $T_{\mathrm{av}}$ is the average temperature of the $T$-range used in experiments:

$\operatorname{BDE}\left(\mathrm{O}-\mathrm{NO}_{2}\right)=38.3 \pm 2.0 \mathrm{kcal} \mathrm{mol}^{-1}$. 
This value is good agreement with the $\mathrm{O}-\mathrm{NO}_{2}$ bond dissociation energy of $38.5 \mathrm{kcal}$ $\mathrm{mol}^{-1}$ in ethyl nitrate, calculated by Khrapkovskii et al. [26] using density-functional B3LYP method and is somewhat lower, although in agreement in the range of the quoted uncertainties, with BDE $\left(\mathrm{O}-\mathrm{NO}_{2}\right)=41.1 \pm 1.0 \mathrm{kcal} \mathrm{mol}^{-1}$ recommended by Luo [27].

\section{CONCLUSIONS}

In this work, kinetics and products of the thermal decomposition of ethyl nitrate were investigated. The reaction rate constant was measured as a function of temperature, $\mathrm{T}=$ (464-673) $\mathrm{K}$, in the pressure range (1-12.5) Torr of helium. Primary product of the nitrate decomposition, $\mathrm{NO}_{2}$, was directly observed and its yield (nearly unity) was measured. The co-product of $\mathrm{NO}_{2}$, ethoxy radical $\mathrm{C}_{2} \mathrm{H}_{5} \mathrm{O}$, was found to rapidly decompose on the timescale of our experiments leading to exclusive production of $\mathrm{CH}_{3}$ radical and formaldehyde in the temperature range of the study. The $\mathrm{O}-\mathrm{NO}_{2}$ bond dissociation energy in ethyl nitrate was determined to be in the range $(38.3 \pm 2.0) \mathrm{kcal}$ $\mathrm{mol}^{-1}$

This study was supported by French National Research Agency (ANR) through project ONCEM (ANR-12BS06-0017-02). J. M. is very grateful for his PhD grant from CAPRYSSES project (ANR-11-LABX-006-01) funded by ANR through the PIA (Programme d'Investissement d'Avenir). 


\section{BIBLIOGRAPHY}

1. Finlayson-Pitts, B. J.; Pitts, J. N. J. Chemistry of the Upper and Lower Atmosphere: Theory, Experiments and Applications; Academic Press: San Diego, 2000.

2. Clemitshaw, K. C.; Williams, J.; Rattigan, O. V.; Shallcross, D. E.; Law, K. S.; Anthony Cox, R. J. Photochem. Photobio. A 1997, 102, 117-126.

3. Clothier, P. Q. E.; Aguda, B. D.; Moise, A.; Pritchard, H. O. Chem. Soc. Rev. 1993, 22, 101-108.

4. Inomata, T.; Griffiths, J. F.; Pappin, A. J. Symp. Int. Combust. 1991, 23, 1759-1766.

5. Toland, A.; Simmie, J. M. Combust. Flame 2003, 132, 556-564.

6. Curran, H. J. Int. J. Chem. Kinet. 2006, 38, 250-275.

7. Phillips, L. Nature 1947, 160, 753-754.

8. Adams, G. K.; Bawn, C. E. H. Trans. Faraday Soc. 1949, 45, 494-499.

9. Levy, J. B. J. Am. Chem. Soc. 1954, 76, 3790-3793.

10. Pollard, F. H.; Marshall, H. S. B.; Pedler, A. E. Trans. Faraday Soc. 1956, 52, 59-68.

11. Houser, T. J.; Lee, B. M. H. J. Phys. Chem. 1967, 71, 3422-3426.

12. Griffiths, J. F.; Gilligan, M. F.; Gray, P. Combust. Flame 1975, 24, 11-19.

13. Mendenhall, G. D.; Golden, D. M.; Benson, S. W. Int. J. Chem. Kinet. 1975, 7, 725737.

14. Zaslonko, I. S.; Smirnov, V. N.; Tereza, A. M. Kinet. Catal. 1993, 34, 531-538.

15. Oxley, J. C.; Smith, J. L.; Rogers, E.; Ye, W.; Aradi, A. A.; Henly, T. J. Energy Fuels 2000, 14, 1252-1264.

16. Morin, J.; Bedjanian, Y. J. Phys. Chem. A 2016, 120, 8037-8043.

17. Morin, J.; Romanias, M. N.; Bedjanian, Y. Int. J. Chem. Kinet. 2015, 47, 629-637.

18. Timonen, R. S.; Seetula, J. A.; Gutman, D. J. Phys. Chem. 1990, 94, 3005-3008.

19. Morin, J.; Bedjanian, Y.; Romanias, M. N. Int. J. Chem. Kinet. 2016, 48, 822-829.

20. Boschan, R.; Merrow, R. T.; van Dolah, R. W. Chem. Rev. 1955, 55, 485-510.

21. Troe, J. Chem. Rev. 2003, 103, 4565-4576.

22. Troe, J. J. Phys. Chem. 1979, 83, 114-126.

23. J. B. Burkholder, S. P. S., J. Abbatt, J. R. Barker, R. E. Huie, C. E. Kolb, M. J. Kurylo, V. L. Orkin, D. M. Wilmouth, P. H. Wine . Chemical Kinetics and Photochemical Data for Use in Atmospheric Studies, Evaluation No. 18; JPL Publication 15-10, Jet Propulsion Laboratory: Pasadena, 2015 http://jpldataeval.jpl.nasa.gov. Accessed November 10, 2016. 
24. Rauk, A.; Boyd, R. J.; Boyd, S. L.; Henry, D. J.; Radom, L. Can. J. Chem. 2003, 81, 431-442.

25. Xu, Z. F.; Xu, K.; Lin, M. C. ChemPhysChem 2009, 10, 972-982.

26. Khrapkovskii, G. M.; Shamsutdinov, T. F.; Chachkov, D. V.; Shamov, A. G. J. Mol. Struct.: THEOCHEM 2004, 686, 185-192.

27. Luo, Y. R. Handbook of Bond Dissociation Energies in Organic Compounds; CRC Press: Boca Raton, FL, 2003. 


\section{TABLES}

Table I Thermal decomposition of ethyl nitrate: summary of the measurements of $k_{0}$ and $k_{\infty}$.

\begin{tabular}{cccl}
\hline$T(\mathrm{~K})$ & $k_{0}\left(10^{-16} \mathrm{~cm}^{3} \text { molecule }^{-1} \mathrm{~s}^{-1}\right)^{a}$ & $k_{\infty}\left(\mathrm{s}^{-1}\right)^{a}$ & Method $^{b}$ \\
\hline 464 & 0.00040 & 0.0026 & $\mathrm{CH}_{3}$ kinetics \\
483 & 0.0015 & 0.019 & $\mathrm{CH}_{3}$ kinetics \\
503 & 0.0058 & 0.099 & $\mathrm{CH}_{3}$ kinetics \\
523 & 0.024 & 0.40 & $\mathrm{CH}_{3}$ kinetics \\
543 & 0.11 & 1.34 & $\mathrm{CH}_{3}$ kinetics \\
563 & 0.26 & 4.48 & $\mathrm{CH}_{3}$ kinetics \\
575 & 0.36 & 13.1 & ENT kinetics \\
583 & 0.74 & 17.0 & $\mathrm{CH}_{3}$ kinetics \\
593 & 0.96 & 39.1 & ENT kinetics \\
614 & 2.30 & 105 & ENT kinetics \\
634 & 6.29 & 243 & ENT kinetics \\
653 & 11.8 & 561 & ENT kinetics \\
673 & 24.0 & 1571 & ENT kinetics \\
\hline
\end{tabular}

${ }^{a}$ estimated uncertainty factor of 1.5 ,

${ }^{b}$ see text.

Table II Thermal decomposition of ethyl nitrate: Arrhenius parameters for $k_{\infty}=A_{\infty} \times \exp (-$ $\left.E_{\infty} / T\right)$ and $k_{0}=A_{0} \times \exp \left(-E_{0} / T\right)$ determined with different values of $F_{\mathrm{c}}$.

\begin{tabular}{cccccc}
\hline$F_{\mathrm{c}}$ & $A_{\infty}\left(10^{16} \mathrm{~s}^{-1}\right)$ & $E_{\infty}(\mathrm{K})$ & $\begin{array}{c}A_{0} \\
\left(10^{-4} \mathrm{~cm}^{3} \mathrm{molecule}^{-1} \mathrm{~s}^{-1}\right)\end{array}$ & $E_{0}(\mathrm{~K})$ & $k_{\text {1cald }} / k_{\text {lexp }}{ }^{a}$ \\
\hline 0,3 & 17.4 & 20794 & 0.58 & 15900 & $0.988 \pm 0.104$ \\
0,4 & 6,86 & 20528 & 0.65 & 16043 & $0.988 \pm 0.106$ \\
0,5 & 2,61 & 20191 & 0.80 & 16221 & $0.989 \pm 0.107$ \\
0,6 & 1,09 & 19867 & 1.01 & 16396 & $0.989 \pm 0.107$ \\
0,7 & 0.49 & 19558 & 1.26 & 16564 & $0.989 \pm 0.107$ \\
0,8 & 0.24 & 19275 & 1.55 & 16715 & $0.989 \pm 0.107$ \\
\hline${ }^{a}$ mean $( \pm 1 \sigma)$ of the ratios of calculated (through expressions (II) and (III)) and experimental values of $k_{1}$
\end{tabular}


Table III Thermal decomposition of ethyl nitrate: summary of the measurements of the reaction rate constant, $k_{1}=A \times \exp (-E / R T)$.

\begin{tabular}{lllll}
\hline Reference & T-range $(\mathrm{K})$ & $\begin{array}{l}\mathrm{P}(\text { Torr }) / \\
\text { bath gas }\end{array}$ & $A\left(10^{15} \mathrm{~s}^{-1}\right)$ & $E\left(\mathrm{kcal} \mathrm{mol}^{-1}\right)$ \\
\hline Adams\&Bawn [8] & $453-488$ & $30-45 /$ ENT & 6.3 & 39.9 \\
Levy [9] & $434-454$ & tens Torr / ENT & 70.8 & 41.2 \\
Polard et al. [10] & $448-482$ & $30-100 /$ ENT & 0.55 & $38.0 \pm 0.4$ \\
Zaslonko et al. [14] & $700-1200$ & $375-750 /$ Ar & 0.04 & 33.0 \\
This study $\left(k_{\infty}\right)$ & $464-673$ & $1.0-12.5 / \mathrm{He}$ & 10.8 & $39.4 \pm 2.0$ \\
\hline
\end{tabular}




\section{FIGURE CAPTIONS}

Figure 1 Diagram of the flow reactor.

Figure 2 Example of kinetics of ethyl nitrate decomposition at different pressures of $\mathrm{He}$ in the reactor: $\mathrm{T}=634 \mathrm{~K}$.

Figure 3 Rate of ENT decomposition measured at different temperatures from kinetics of ENT loss as a function of total pressure of He. Uncertainty on $k_{1}$ (nearly 10\%) corresponds to the size of symbols. Continuous lines represent the best fit to the experimental data according to equations (II) and (III) with $F_{\mathrm{c}}=0.6$ and two varied parameters, $k_{0}$ and $k_{\infty}$.

Figure 4 Kinetics of ethyl nitrate decomposition and three reaction products formation recorded at $\mathrm{T}=595 \mathrm{~K}$ and $\mathrm{P}=12.4$ Torr.

Figure 5 Concentration of the products formed upon decomposition of ethyl nitrate as a function of consumed concentration of ENT: $\mathrm{P}=12$ Torr, $\mathrm{T}=700 \mathrm{~K}$. Error bars correspond to $10 \%$ uncertainty on the measurements of the ENT and product concentrations.

Figure 6 Kinetics of $\mathrm{CH}_{3}$ production upon ENT decomposition measured at different pressures in the reactor: $\mathrm{T}=583 \mathrm{~K},[\mathrm{ENT}]=1.0 \times 10^{13}$ molecule $\mathrm{cm}^{-3}$.

Figure 7 Rate constant of $\mathrm{CH}_{3}$ production upon ENT decomposition as a function of total pressure of $\mathrm{He}$ at different temperatures in the reactor. Height of the symbols corresponds to nearly $15 \%$ uncertainty on $k_{1}$.

Figure 8 Temperature dependence of the high and low pressure limits of $k_{1}$. 


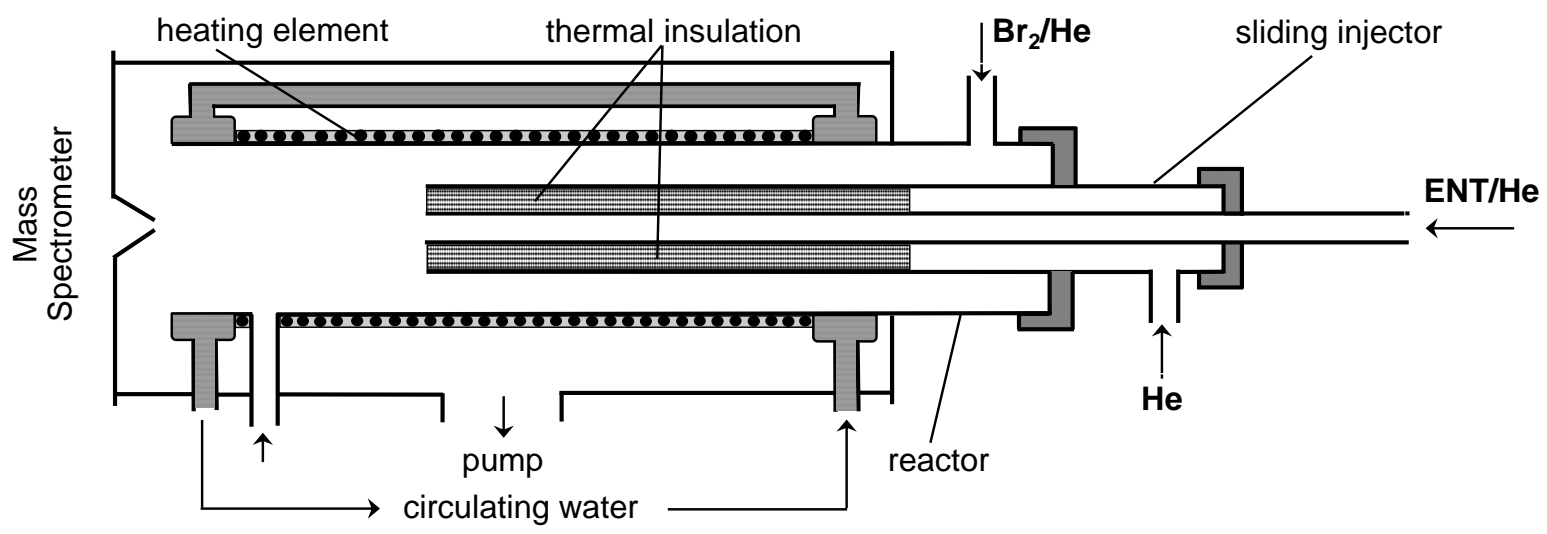

Figure 1

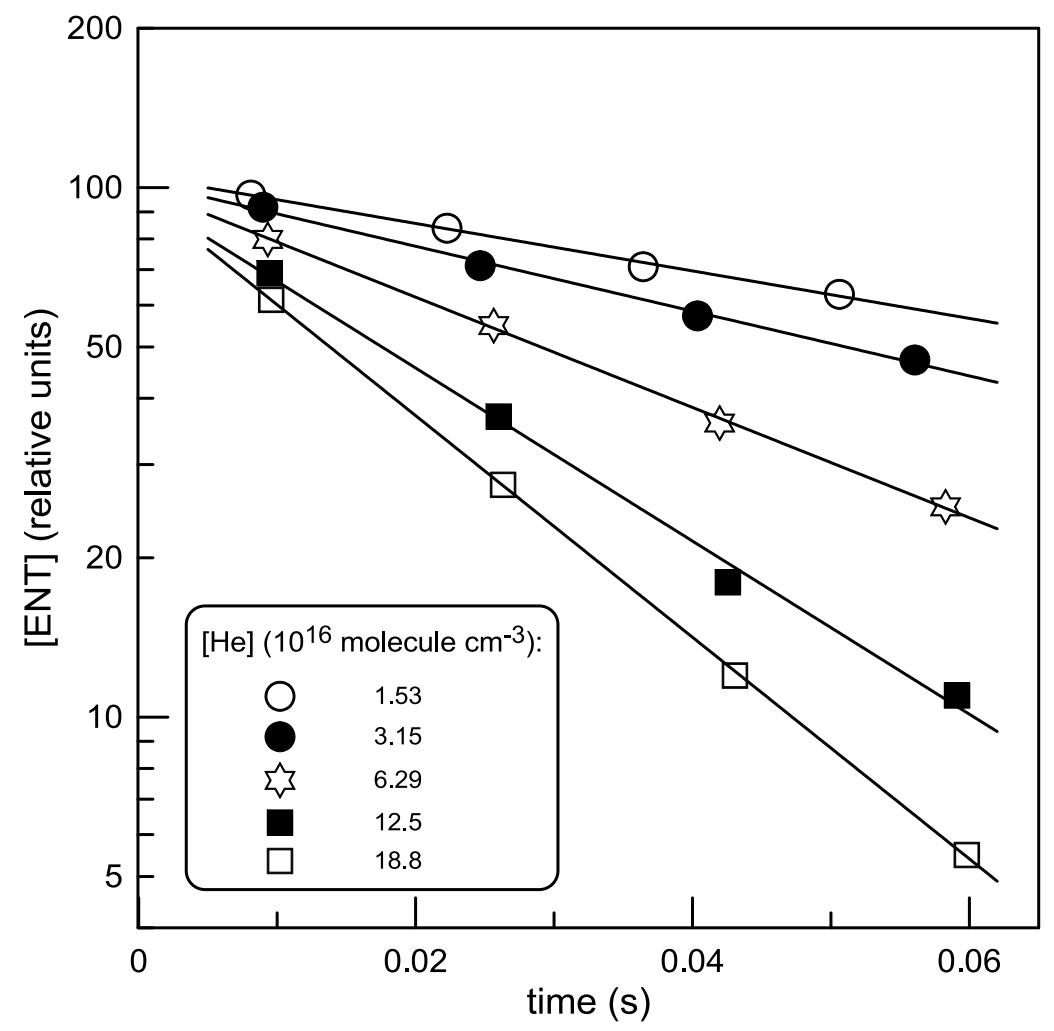

Figure 2 


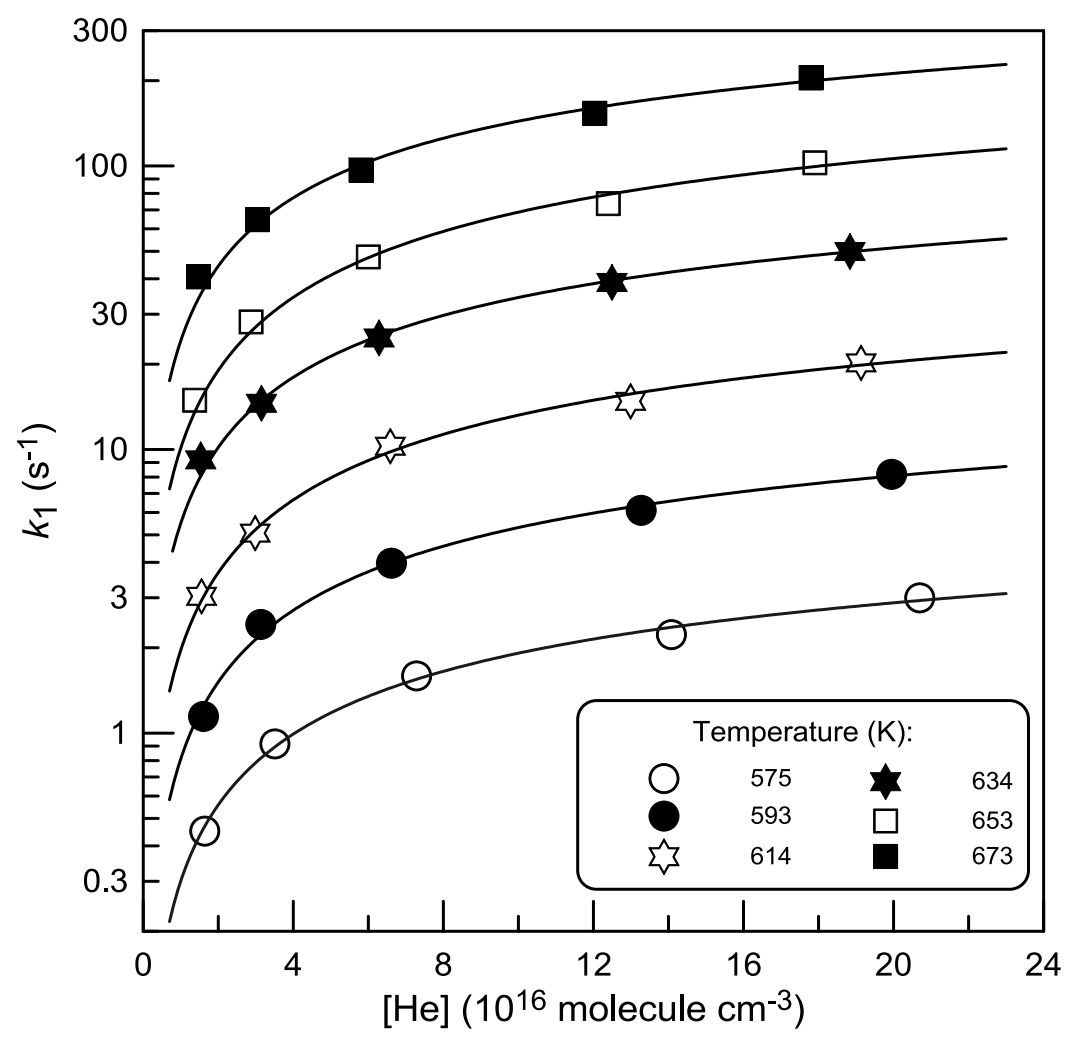

Figure 3

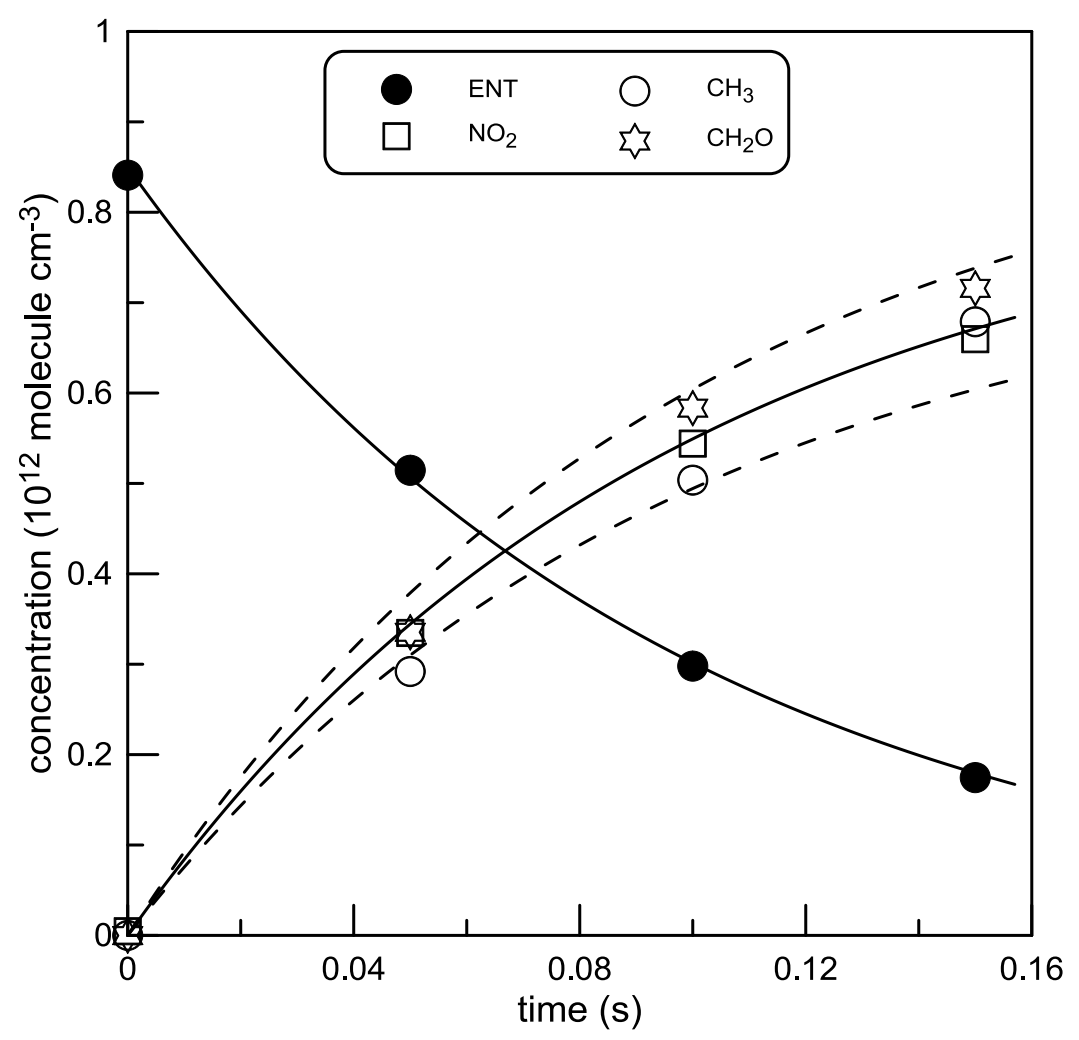

Figure 4 


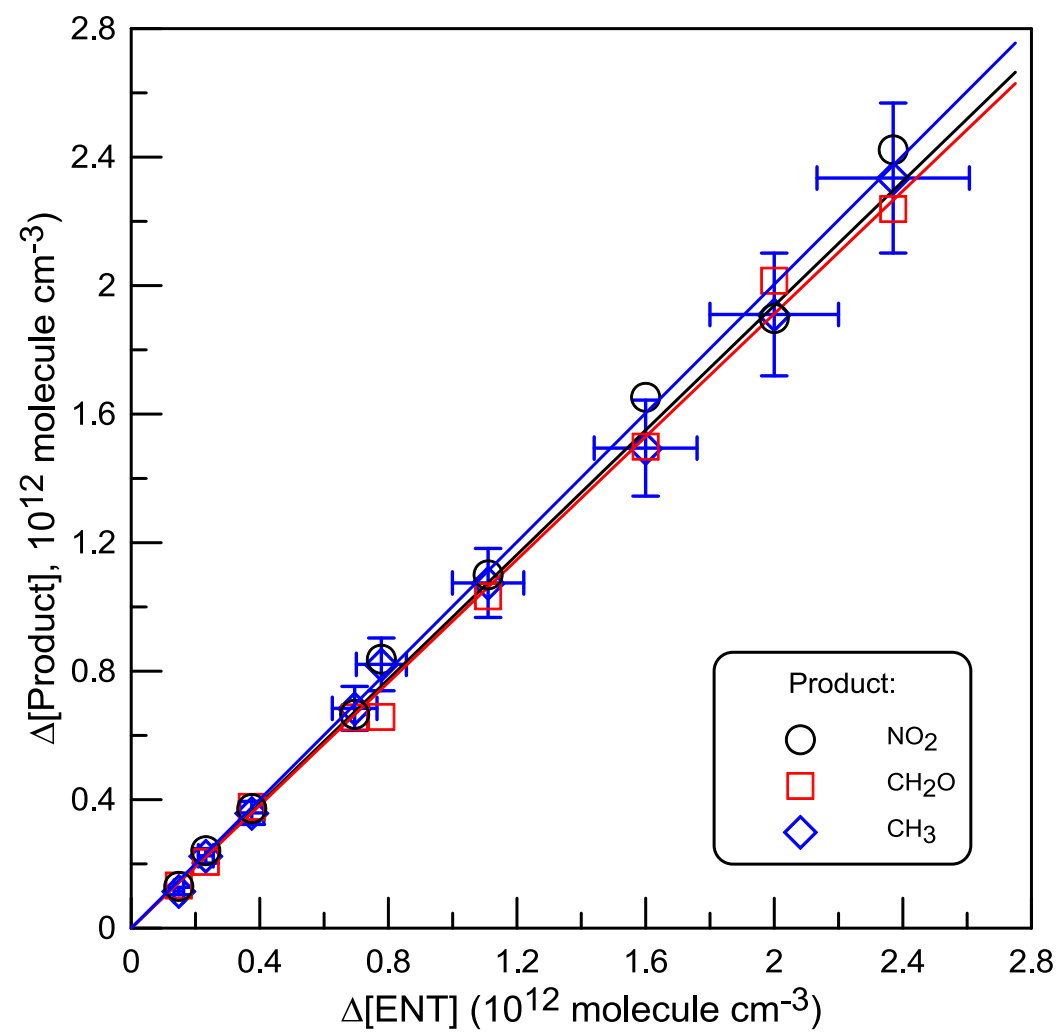

Figure 5

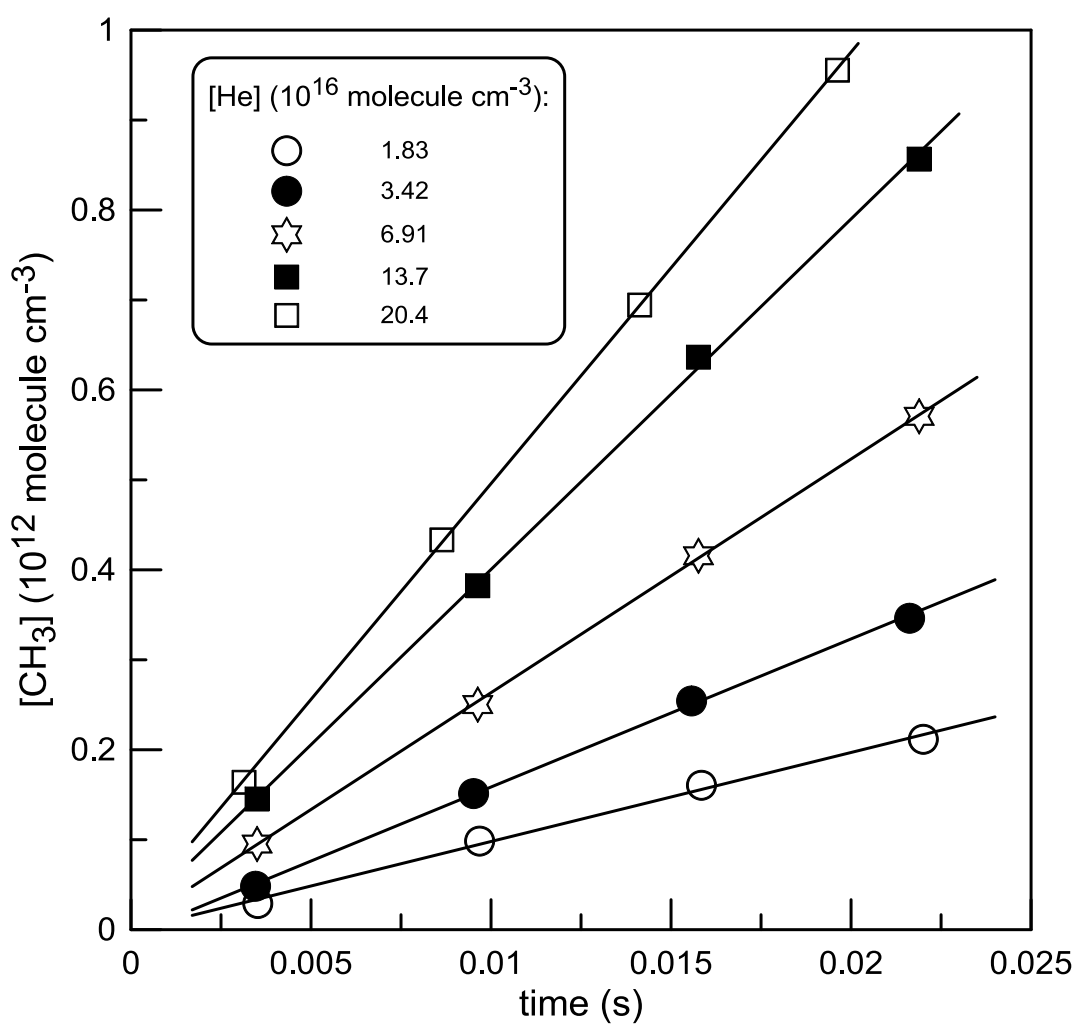

Figure 6 


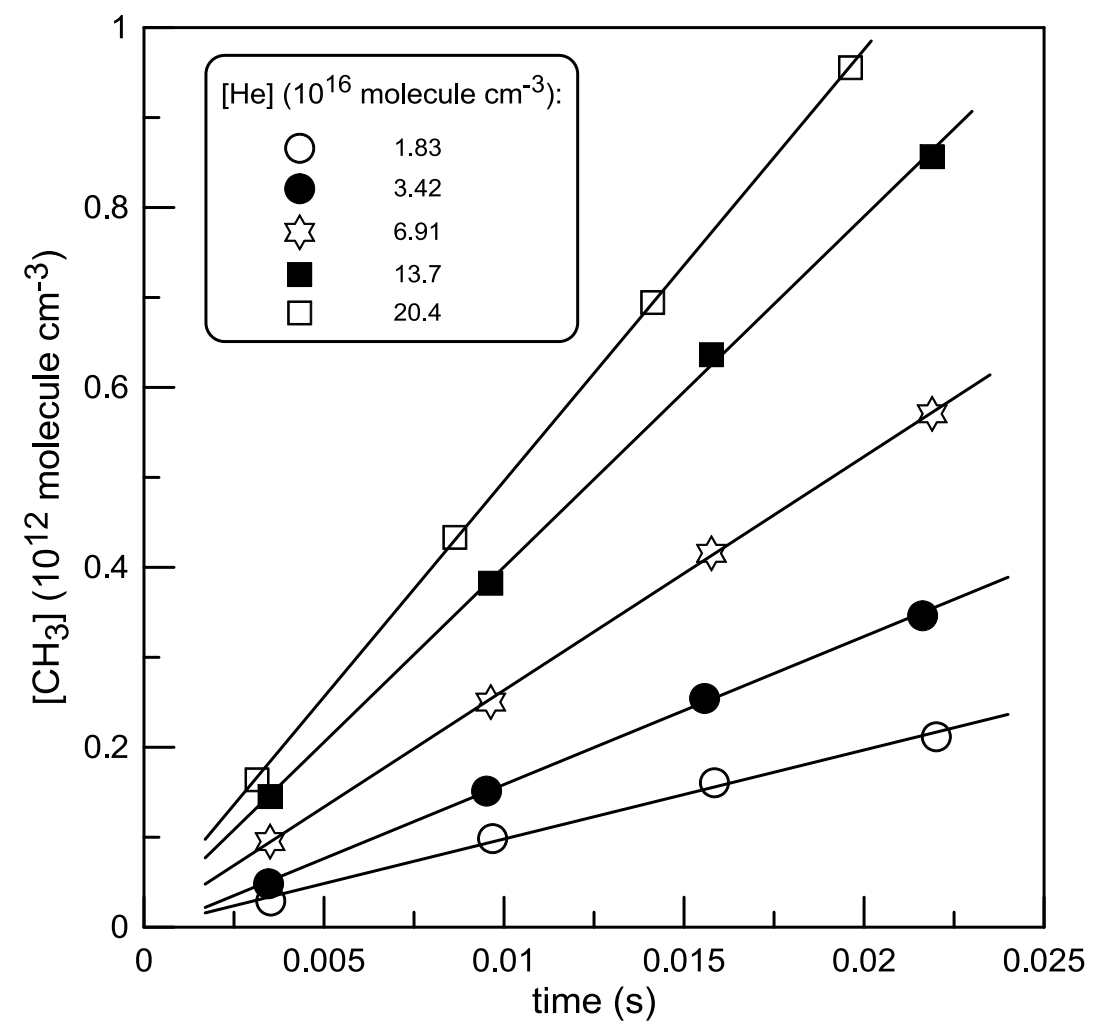

Figure 7

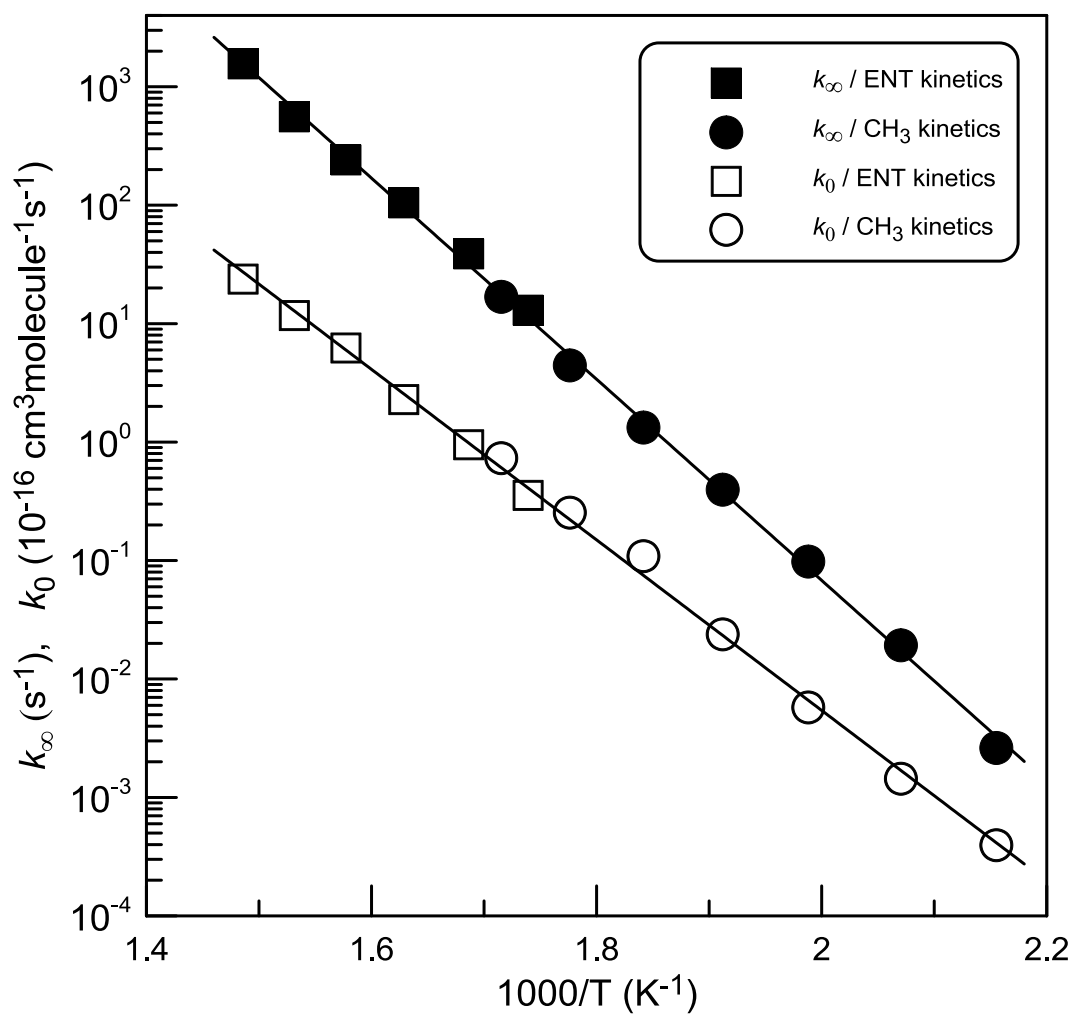

Figure 8 